\title{
JUURNAL.RU
}

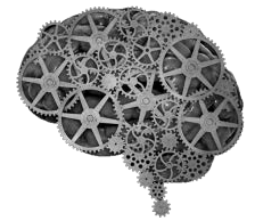

COMPANY GROUP "INTELLEKT"

\author{
Голосов П.Е., Горелов В.И., Федосеев А.И., Карелова О.Л. \\ Российская академия народного хозяйства и государственной службы при Президенте

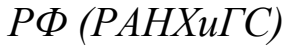 \\ Москва, Россия
}

doi: 10.18411/lj2016-7-2-04

idsp 000001: lj2016-16-2-04

\section{Россия на перепутье}

Россия сейчас находится на перепутье. С одной стороны, наблюдается явное неприятие политики России развитыми странами, а с другой стороны просматривается внутреннее разочарование тем путем развития страны, по которому она идет в последние годы. Нельзя сказать, что эта ситуация образовалась неожиданно. Было много сигналов, в том числе и в ежегодных посланиях Президента РФ, но ситуация казалась управляемой и в соответствии с базовыми принципами менеджмента не требовала оперативного вмешательства. Сейчас пришло время решений, возник естественный вопрос - что делать?

Для того чтобы это понять, необходимо провести анализ состояния страны и еe возможностей.Для оценки состояния страны применим методику, используемую в [1]. Суть этой методики в следующем: Сначала выбирается наиболее полный набор характеристик состояния общества, описывающих экономическую, экологическую и социальную сферу жизни страны, а затем из статистической базы выбираются индикаторы, характеризующие состояние этих характеристик. Поскольку все характеристики являются частью единого целого, то они влияют друг на друга, усиливая или ослабляя результаты воздействия какой-то характеристики на развитиестраны и общества. По сути дела, статистическая база определяет вес влияния индикатора на развитие, исходя из 
потребностей общества. Чем больше вес индикатора, тем больше необходимость воздействия на этот индикатор для устойчивого развития. Именно это обстоятельство позволяет определить наиболее эффективные пути развития [2] и ответить на вопрос «что делать».

Для исследования внешней политики России качестве характеристик и их индикаторов состояния (в скобках) стран были использованы:

1. ВВП страны

2. Уровень образования, рассчитанный по методике Юнеско

3. Долг страны (в процентах от ВВП)

4. Социальная заболеваемость (туберкулез) - (число заболеваний на 10000 чел. населения).

5. Производство энергии (в денежном эквиваленте).

6. Добыча сырья(в денежном эквиваленте).

7. Инфраструктура (в качестве индикатора инфраструктуры был принят коэффициент плотности железнодорожных и автомобильных дорог на квадратный километр территории).

8. Суммарные инвестиции (как внутренние, так и внешние)

9. Энергетические возможности (индикатором энергетических возможностей было принято отношение ввозимой или экспортируемой энергии к используемой внутри страны).

10. Сырьевые возможности (индикатором сырьевых возможностей было выбрано отношение разности между экспортом и импортом сырья к объему производства в машиностроении и химической промышленности).

11. Численность населения

12. Бедность - (индекс Джини)

13. Уровень инновационного использования науки (доход, полученный за использование разработок отечественных исследователей в своей стране). 
14. Бюджет страны

15. Качество жизни (индекс развития человеческого потенциала).

16. Рабочий потенциал - (численность работающих).

Далее была построена матрица мягких связейустойчивого влияния одних индикаторов на другие (таблица 1). Устойчивые связи выявлялись по статистическим базам разных лет и по их разбиениям так, чтобы их надежность была не менее $90 \%$.

В представленной матрице элементы строк и столбцов соответствуют порядковому номеру характеристик состояния общества.

Таблица 1

Матрииа мягких связей устойчивого влияния одних индикаторов на другие

\begin{tabular}{|c|c|c|c|c|c|c|c|c|c|c|c|c|c|c|c|c|}
\hline № & $\mathbf{1}$ & $\mathbf{2}$ & $\mathbf{3}$ & $\mathbf{4}$ & $\mathbf{5}$ & $\mathbf{6}$ & $\mathbf{7}$ & $\mathbf{8}$ & $\mathbf{9}$ & $\mathbf{1 0}$ & $\mathbf{1 1}$ & $\mathbf{1 2}$ & $\mathbf{1 3}$ & $\mathbf{1 4}$ & $\mathbf{1 5}$ & $\mathbf{1 6}$ \\
\hline $\mathbf{1}$ & & 1 & & & & & & & & & & & 1 & 1 & 1 & \\
\hline $\mathbf{2}$ & & & 1 & & & & & & 1 & & & & & & 1 & 1 \\
\hline $\mathbf{3}$ & & & & & & & & & & & & & & & 1 & \\
\hline $\mathbf{4}$ & & & 1 & & & & & & & & & & & & & \\
\hline $\mathbf{5}$ & 1 & & & & & 1 & & 1 & & & & & & & & 1 \\
\hline $\mathbf{6}$ & 1 & & & & & & 1 & 1 & & & & & & & & 1 \\
\hline $\mathbf{7}$ & 1 & & 1 & & & & & 1 & & & & & & & 1 & \\
\hline $\mathbf{8}$ & 1 & & & & & & & & & & & & 1 & & & \\
\hline $\mathbf{9}$ & & & & & & & & & & 1 & & & & & & \\
\hline $\mathbf{1 0}$ & & & & & & & & & & & & 1 & & & & \\
\hline $\mathbf{1 1}$ & & 1 & & & 1 & & & & & & & & & & & \\
\hline $\mathbf{1 2}$ & & 1 & 1 & 1 & & & & 1 & & & & & & & & \\
\hline $\mathbf{1 3}$ & & 1 & & & & & & & & & & & & & & \\
\hline $\mathbf{1 4}$ & & 1 & 1 & & & & 1 & & & & & & & & & \\
\hline $\mathbf{1 5}$ & & & & & & & & & & & & 1 & & & & \\
\hline $\mathbf{1 6}$ & & & & & & & & 1 & & & 1 & & & 1 & & \\
\hline
\end{tabular}

Замечание: При выполнении расчетов в представленной матрице единицы заменялись коэффициентами регрессии, найденные по данным рассматриваемой статистической базы.

Результаты расчетов[1]за разные годы показывают следующую картину.

1. В мире наблюдается постоянное противостояние развитых и остальных стран для сохранения существующего порядка. Более развитые страны занимаются в основном переработкой сырья и циклом производства инновационных продуктов, в то время как остальные страны являются поставщиками сырья и человеческих 
ресурсов. Идет непрерывная война между развитыми странами и остальным мировым сообществом за ресурсную базу и рынки сбыта.

2. Начиная с миллениума, мир стал стремительно меняться, но поразному: Развитые страны все время находятся около точки кризиса, потому что чувствительность изменения границ индикаторов у них стран мала, в то время как остальные страны находятся вдали от опасных зон.

3. Развивающиеся страны тянутся за развитыми, повторяя их тенденции, достижения и ошибки, приближаясь к кризисной фазе. При этом они все больше отстают в своем развитии от развитых стран.

4. Россия - не исключение. Вписываясь в международное пространство, она выполняет свою роль сырьевой страны.

В качестве примера рассмотрим весовые коэффициенты влияния, приведенные в таблице 2.

Таблица 2

Весовые коэффициенты влияния индикаторов на развитие стран

\begin{tabular}{|c|c|c|c|}
\hline 2000г. & Мир в целом & $\begin{array}{c}\text { Страны - ресурсные } \\
\text { экспортеры }\end{array}$ & $\begin{array}{c}\text { Развитые } \\
\text { страны }\end{array}$ \\
\hline $\mathbf{1}$ & $\mathbf{2}$ & $\mathbf{3}$ & $\mathbf{4}$ \\
\hline Образование & 7,27129 & 5,99441 & 8,48665 \\
\hline Внутренняя энергия & 5,19433 & 6,58642 & 4,16181 \\
\hline Добыча сырья & 3,77306 & 4,36931 & 4,47787 \\
\hline Рабочий потенциал & 3,11753 & 4,10581 & 3,30029 \\
\hline Демография & 2,96224 & 3,90155 & 3,31478 \\
\hline Качество жизни & 2,31044 & 4,2444 & 2,57016 \\
\hline ВВП & 2,23819 & 1,78019 & 2,06376 \\
\hline Инфраструктура & 1,56816 & 1,75966 & 1,7561 \\
\hline Инвестиции & 0,77448 & 0,76882 & 0,72783 \\
\hline Сырьевые возможности & 0,70011 & 0,12233 & 0,36439 \\
\hline Энергетические & 0,53863 & 0,16711 & 0,00359 \\
\hline возможности & 0,49471 & 1,39201 & 0,3608 \\
\hline Бюджет страны & 0,12092 & 0,11642 & 0,12289 \\
\hline Гонорар ученых & $-0,56875$ & $-0,47526$ & $-0,48738$ \\
\hline Долг & $-0,6064$ & $-0,56673$ & $-0,65541$ \\
\hline Заболевания & $-2,96161$ & $-3,11449$ & $-3,46183$ \\
\hline Бедность & \multicolumn{2}{|c|}{} \\
\hline
\end{tabular}


Из таблицы мы видим, что главным приоритетом развитых стан является повышение уровня образования для разработки, производства и внедрения новых технологий и товаров, в то время как для стран - ресурсных экспортеров - добыча и производство энергии, поэтому и влияние уровня образования у них ниже.Потребность в росте ВВП больше у развитых стран, также, как и борьба с расслоением общества. В отличие от развитых стран, странам - ресурсным экспортерам помимо решения ресурсных задач, необходимо больше внимания уделять росту качества жизни, поскольку уровень расслоения общества в них существенно возрастает.

Получается замкнутый круг. Для лидерства необходимо повышать уровень жизни населения через разработку и внедрение новых технологий. Чтобы эти разработки продать, необходимо повышать качество жизни и остальных стран, используя при этом их энергетические, сырьевые и человеческие ресурсы. Однако есть и другой путь лидерства - теория управляемого хаоса. В этом случае, введя точки напряжения, можно сохранять лидерство. Сейчас отчетливо видны такие точки напряженности (плохо просчитанные и имеющие далеко идущие последствия). Более того, понятно, что эта методика будет и дальше применяться. Механизм известен - цветные революции. По существу, лозунги цветных революций - красивая сказка. В статье [3] показано, что демократия состояние развитого общества и ее никак нельзя перенести в слаборазвитую страну. Но в сказки верят. Окружающие страны несут огромные потери и их развитие замедляется. Посмотрите на ситуацию в Европе. Заметьте, в Южной Америке банановые революции давно не происходят. Борьба за сохранения мирового порядка в самом разгаре, и это далеко не последняя партия, как утверждается в [4].

История напряженности настоящего времени, на наш взгляд, началась с реализации изменения состава собственников газа и нефти, которым были нужны новые рынки сбыта. В качестве рынка сбыта была выбрана Европа. Отсюда - события в Афганистане, Ираке, Ливии, Сирии и Украине. Почему ЕС 
поддержал это начинание? А ему все равно, кто будет поставлять энергоресурсы, главное - чтобы ресурсы были по приемлемой цене. Изюминка проекта состоит в том, что попутно очаги напряженности отвлекают финансовые ресурсы и замедляют развитие окружающих стран.

Россия в случае успеха проекта попадает в крайне тяжелое положение. Мы являемсяресурснымпоставщиком, и подобное перераспределение создает угрозу безопасности страны, сначала как экономическую, а потом и территориальную. Поэтому, присоединение Крыма, занимающего стратегическую позицию, было вынужденным, но правильным шагом.Таким же защитным и вынужденным шагом была помощь ДНР и ЛНР. Поскольку проект еще не закончен, то точка напряженности на Украине сохранится. Никто из развитых стран не хочет вкладывать большие деньги в этот проект, следовательно, конфликт будет на износ - постоянным, но вялотекущим.Думается, что через несколько лет Украину пустят в ЕС. Следующими логичными шагами будут отсекания Южного потока и второй ветки Северного.

Идея помощи Сирии запоздала. В самом начале конфликта было ясно, что Россию в него будут втягивать, и именно тогда необходимо было определять меру поддержки сирийского правительства. Одним из основополагающих принципов менеджмента является следующее правило: Правильное решение, принятое с опозданием, является ошибкой (Ли Якокка). Конечно, мы не сможем организовать большую коалицию по борьбе с ИДИШ. Просто она уже существует. Мы влезли, перемешали всем карты, нам услужливо дали возможность поругаться с Турцией (сыграли на самолюбии двух президентов), а теперь терпеливо ждут, когда сумеют использовать наш порыв в свою пользу. Вариантов много, но мы пока проигрываем, поскольку Б. Асад уходит, а друзей в оппозиции мы еще не завели.С Турцией надо помириться.

1. Как мы видим, на международной арене Россия ведет тактическую борьбу за свое выживание, и, конечно, не является агрессором. Одновременно с этим она добросовестно выполняет свои 
международные обязательства. Необходимо отдать должное нашему Президенту за его работу по встраиванию России в мировую систему отношений и отстаиванию ее интересов.

2. Реализация мировых проектов требует больших финансовых затрат и времени. Трудно представить, что такие проекты под силу любому правительству. Такое впечатление, что где-то на планете есть мощнейший центр, который строит политику мира таким образом, что для всех, кроме него, существует выбор либо плохого, либо или очень плохого решения. В область его интересов входит,скорее всего, США и экономическая элита развитых стран, а вот интересы всех остальных не учитываются.

3. Такой порядок не признает никаких законов и правил, кроме своих.Более того, он не позволяет принять выверенные стратегические решения, направленные наразвитие человечества. Конечно, его необходимо менять, поскольку он является тормозом на пути развитиячеловечества. В.В. Путин правильно поднимает вопросы изменения существующего мирового порядка, стремясь к созданию более эффективной структуры мировых отношений через разумную реконструкцию. ПосмотритеречиПрезидента на Ассамблее ООН, Мюнхенское выступление, речь в Валдайском клубе. Даже за это скромное пожелание В.В. Путина демонизируют, рисуя образ разрушителя.

4. Человечеству нужна новая стратегия и новый лозунг развития. Приведем слова А.Эйнштейна: «Вы никогда не сумеете решить проблему, если сохраните тоже мышление и тот же подход, что привел вас к этой проблеме». И этим новым вектором должно являться мирное устойчивое развитие человечества.

Для того чтобы понять, что происходит внутри России и каковы ее внутренние приоритеты развития, используем базу статистики Госкомстата. В 
качестве примера рассмотримсистемные веса влияния на развитие страны через развитие регионов за 2003 - 2005 года, приведенные в табл. 3.

Таблица 3.

Системные веса влияния

\begin{tabular}{|c|c|c|c|c|c|}
\hline 2003 г. & Критерий & 2004 г. & Критерий & 2005 г. & Критерий \\
\hline 4,5437 & Рабочий потенциал & 6,3751 & $\begin{array}{l}\text { Индекс } \\
\text { Джини } \\
\end{array}$ & 4,5814 & Образование \\
\hline 3,8864 & Демография & 5,7699 & Образование & 3,6138 & $\begin{array}{c}\text { Индекс } \\
\text { Джини } \\
\end{array}$ \\
\hline 3,8201 & Потребление энергии & 2,9834 & Рабочий потенциал & 2,7210 & Рабочий потенциал \\
\hline 2,3455 & Образование & 1,8510 & Потребление сырья & 1,7854 & Потребление сырья \\
\hline 0,9825 & $\begin{array}{c}\text { Сырьевые } \\
\text { возможности }\end{array}$ & 1,3366 & Инфраструктура & 1,6000 & Демография \\
\hline 0,4448 & $\begin{array}{c}\text { Энергетические } \\
\text { возможности }\end{array}$ & 1,3007 & Демография & 1,1531 & Инфраструктура \\
\hline 0,4034 & Потребление сырья & 1,0942 & $\begin{array}{c}\text { Сырьевые } \\
\text { возможности }\end{array}$ & 1,0682 & $\begin{array}{c}\text { Сырьевые } \\
\text { возможности }\end{array}$ \\
\hline 0,3967 & Инфраструктура & 0,9591 & Потребление энергии & 1,0321 & $\begin{array}{c}\text { Потребление } \\
\text { энергии }\end{array}$ \\
\hline 0,2513 & Качество жизни & 0,5018 & ВРП & 0,5471 & $\begin{array}{c}\text { Энергетические } \\
\text { возможности }\end{array}$ \\
\hline 0,1025 & ВРП & 0,4572 & Инвестиции & 0,3217 & Качество жизни \\
\hline 0,1023 & Инвестиции & 0,3421 & Бюджет региона & 0,3171 & Инвестиции \\
\hline$-0,0209$ & Загрязнение & 0,1912 & $\begin{array}{c}\text { Энергетические } \\
\text { возможности }\end{array}$ & 0,2696 & ВРП \\
\hline$-0,0335$ & Бюджет региона & 0,1757 & Качество жизни & 0,1410 & Бюджет региона \\
\hline$-0,2268$ & Сальдо регионов & $-0,0089$ & Загрязнение & $-0,0226$ & Загрязнение \\
\hline$-0,7683$ & Индекс Джини & $-0,7751$ & Заболеваемость & $-0,6486$ & Сальдо регионов \\
\hline$-0,9299$ & Заболеваемость & $-1,0404$ & Сальдо регионов & $-0,7392$ & Заболеваемость \\
\hline$-1,0083$ & Патологии & $-1,2437$ & Патологии & $-1,2008$ & Патологии \\
\hline
\end{tabular}

По значимости приоритетов, на первом месте в 2003 году стоит численность работающих.

Проведемкраткий анализ этого индикатора. В России экономически активного населения в 2003 году около 72 млн. человек - приблизительно 50\% населения страны. Число работающих около 65 млн. человек. Получается, что почти все работоспособное население работает и стремится работать еще. Все работают, а потребность - еще больше. При этом в промышленности занято около 22\% работающего населения, в сельском хозяйстве - около 12\%, бюджетников - около 25\%, остальные - в торговле и сфере услуг. В 2014 году эти цифры соответственно 76 млн. человек - более 50\% населения, около 72 млн. человек работают. До 8\% упала цифра занятости в сельском хозяйстве, до $23 \%$ сократилось число бюджетников, на $6 \%$ увеличилась численность работающих в сфере торговли и услуг.Население страны выросло за эти годы чуть более миллиона человек, а численность работающего населения выросла на 
5 млн. человек. Изменения обусловлены в основном тем, что качество жизни населения за этот промежуток времени существенно возросло, поскольку темпы роста заработной платы были выше уровня инфляции. Однако по-прежнему, скопить денег на достойную старость людям не удается, большинствуприходится работать и на пенсии.Во всех расчетах в верхней части таблицы находятся рабочий потенциал (люди нуждаются в рабочих местах) и индекс Джини (расслоение общества), в нижней части таблицы обращает на себя внимание усиление влияния патологий (числа новорожденных с патологиями) и малое влияние загрязнений на развитие регионов. В средней части таблицы можно отметить неэффективность вложения инвестиций (на рубль инвестиций около 30 копеек отдачи) и малое (практически никакое) влияние бюджетов регионов на свое развитие.

Отсюда следует следующий вывод: Регионы, в основной массе, в своем развитииживут за счет федерального центра и зависят от его финансовых потоков.При хорошем наполнении федерального бюджета потоки больше. Сколько обоснуют, столько и потратят. Своих денег на развитие у них почти нет, особого стимула развиваться не существует, поскольку большая часть прибыли уходит из региона. Система отношений между муниципальной и региональной властью выстроена аналогично верхнему уровню иерархии. До муниципальной власти деньги на развитие практически не доходят (потоки небольшие и расходуются в основном на региональные проекты). Поэтому на нижнем звене иерархии сигнал затухает, и до населения почти не доходит. Вокруг этих потоков в региональных и муниципальных ветвях власти формируется элита, живущая по своим местным правилам и законам, а сами эти законы могут весьма сильно отличаться от федеральных (примеров масса). В результате получаем три уровня власти плохо скоординированные между собой. Слабая обратная связь. Если между федеральной и региональной властью еще налажено какое-то взаимодействие, то до нижнего уровня федеральная власть не достает. Сигнал плохо проходит что туда, что обратно. Фактически население 
является заложником местных элит, и занято, в основном, поиском работы. На местах мало работающих предприятий, людей из сельской местности оттягивают крупные центры, неопределенность ситуации и низкий уровень качества жизни вызывает рост влияния патологий на развитие. Необходимо отметить, что в «тучные годы» государство, как крупнейший работодатель, обеспечивало повышение уровня жизни ростом зарплат бюджетников и повышением пенсий и система худо - бедно работала.Сейчас ситуация другая бюджета на всех не хватает и систему необходимо приводить в порядок, отлаживая обратную связь.

Ряд вызовов, от решения которых зависит развитие государства через развитие регионов.

1. Идеология развития. До сих пор в стране нет идеологии развития. Наверное, главное в решении всех этих проблем - социальная ответственность государства и социальная направленность координации всего комплекса решаемых задач. Можно всех объединить для развития страны? Можно, с помощью национальной идеи: «Устойчивое развитие» или, что одно и то же, «Сильное государство с богатым и здоровым населением». Но задействовать человеческий ресурс, изобретательность и смекалку можно будет только тогда, когда на деле, а не на словах все население через работу всей иерархии ветвей власти увидит заботу о каждом человеке от ребенка до старика, когда каждый поймет, что его старания будут оценены должным образом.

2. Совершенствование системы управления. Начнем с того, что выстроенную систему ломать нельзя. Все чиновники - это наши люди и других взять негде. Необходимо наладить обратную связь. Для этой цели лучше всего бы подошла, на наш взгляд, иерархическая система оценки развития регионов, аналогичная приведенной выше. Сравнивая вышеприведенные таблицы с расчетами, можно видеть, что на разных 
иерархических уровнях приоритеты развития различны, но реализация каждого из иерархических приоритетов развития усиливает развитие системы в целом. У такой оценки много плюсов.

- Прежде всего, она формирует приоритетные задачи развития на каждом уровне власти. Каждой из ветвей власти становится понятным, чем ей заниматься.

- Выстраивается сквозная иерархия приоритетов.

- В случае пересечения приоритетов происходит регулирование бюджетных потоков.

- Оценку усилий можно просчитать, определить узкие места и принять необходимые меры. На это необходимых инструментов у государства достаточно.

- При расчетах оценки ошибка в данных, если она присутствует, всегда обнаруживается.

3. Налоги. Для развития необходимо увеличение доходной базы в виде налогов. Казалось бы, все просто: создавайте новые рабочие места и перераспределяйте налоги. Каждый год перераспределяют налоговую часть бюджета и создают рабочие места. А проблема как была, так и остается. Здесь мы намеренно не будем касаться вопросов наполнения бюджетов различных уровней. Проблемы лежат в другой плоскости. Внедряя капитализм и демократию, мы как-то «потеряли» основной финансовый инструмент контроля демократического общества равенство доходов и расходов любого члена этого общества, от рабочего до президента страны. Развитые страны очень серьезно относятся к контролю над финансами и, как следствие, к репутации каждого человека. Может ли государство определить, является ли каждый гражданин государства добросовестным налогоплательщиком или нет, и принять соответствующие меры? Конечно. Почему же это не сделано до сих пор? Усиление инструмента финансового контроля - 
прерогатива федеральной власти. Разработка необходимых законов дело Государственной думы. Принятие таких законов, прежде всего, относится к внутренней политики государства.

Почему создание именно такого инструмента финансового контроля представляется сегодня одной из важнейших задач развития общества?

- Отсутствие инструмента финансового контроля в виде равенства доходов и расходов разрушает страну с идеологической позиции. Начинают работать двойные стандарты, процветает ложь, жизнь по понятиям и т.д.

- Происходит разрушение страны с финансовой позиции. Отсутствие должного финансового контроля и позволяет не перечислять налоги государству, т.е. оставляет полуголодными стариков, детей, бюджетников. Недаром получили распространение черные зарплаты. Человек, работающий на государство (врач, учитель и т.д.), остается беззащитным, в то время как человек, работающий на себя, защищенным. Происходит смена идеологии, и в этой новой идеологии нет места государству. Возникает взрывоопасная и неустойчивая ситуация.

- При отсутствии подобного контроля в стране нет демократических свобод, а есть анархические свободы (кто сильнее), разрушающие устои государства. Если государство провозгласило курс на демократизацию общества, то этот курс необходимо выполнять.

- Отсутствие контроля над доходами и расходами - это пример бездуховности для молодого поколения. Сегодня мы начинаем терять наше будущее поколение в возрасте 12-13 лет. Именно в этом возрасте происходит осознание значимости образования, положения личности в обществе. Как следствие, около 30 - 50\% школьников старших классов не могут осмыслить предлагаемый им учебный 
материал. Они думают, что образование им просто не понадобится, поскольку в ходу другие методы. А им жить и развивать страну.

- Отсутствие контроля над доходами и расходами - это непрерывный передел собственности. Любая крупная собственность в нашей стране неустойчива, потому что создавалась с многочисленными нарушениями и, как правило, на государственные деньги. Где-то за счет дельцов от власти, где-то от криминального беспредела, а может и от всего вместе. Обратите внимание, одно из главных пожеланий крупного капитала - сохранение собственности. И государство с этим соглашается. Никто не ставит вопрос о сохранении честно нажитой собственности. А это означает, что передел будет продолжаться.

- Из-за отсутствия контроля над доходами и расходами наша внутренняя норма жизни сегодня не имеет ничего общего с нормами внутренней жизни развитых стран. Получается, что развитые страны воспитывают свое население в рамках соблюдения одних законов, а мы - в рамках других законов. Думается, это одна из причин, по которой ЕС поддерживает санкции против России. Таким образом, мы опять за железным занавесом, но уже поставленным не нами. Заметьте, Европа уже начала компанию по проверке доходов нашей элиты, лежащих в зарубежных банках. И дальше они будут арестовываться и изыматься.

Одной из главных задач сегодняшнего дня является введение и обязательное исполнение инструментов финансового контроля общества и государства в виде равенства доходов и расходов каждого члена общества без всяких исключений с соответствующим наказанием за его нарушение без срока давности. Именно с этого начинается демократия. Для выживания России необходимо демократическое и цивилизованное государство, именно этого требует большинство населения страны, пусть и неосознанно.

Резюмируя сказанное, можно сделать следующие выводы: 
- Внешняя политика России вписывается в развитие мирового сообщества, она предсказуема и, в основном, понятна.

- Сегодняшний этап политики характеризуется стремлением страны отстоять свою независимость. Налицо конфликт интересов. Конфликт будет решаться в экономической плоскости, путем экономического давления как на страну, таки на ее отдельных граждан. Победа в этом конфликте возможна только через быстрое и эффективное развитие государства.

- Для развития государства нужна новая идеология и новая внутренняя политика - устойчивое развитие.

- Внутренняя политика включает две базовых составляющих: «моральный климат» в стране и собственно финансовоэкономическую политику.

«Моральный климат» определяется разделением населения на две разнополюсных группы. Деление людей проходит по линии «избранные» «остальные», причем избранным можно больше. «Избранные» живут по своим законам, а «остальные» - по другим. Надо убирать конфликт интересов, «избранным» необходимо подстраиваться под интересы своего населения.

- Из анализа системы следует, что отсутствие финансового контроля над равенством доходов и расходов является главным тормозом осуществления «экономического чуда», т.е. быстрого развития страны. Более того, отсутствие этого механизма вызывает все большее отставание страны от развитых стран и чревато большими социальными потрясениями. По сути, мы сами создаем новый железный занавес как внутри страны, так и вокруг нее.

- Моральное состояние общества дает стабильные условия для развития важнейшего ресурса страны - человеческого потенциала, 
т.е. того потенциала, который определяет будущее страны и ее возможности перехода к обществу, основанному на знаниях.

- Неутешительный вывод заключается в том, что, пока не будет изменена система совершенствования управления и не налажен контроль выполнения решений особой пользы от всех экономических преобразований не будет. Страна, продолжая двигаться вперед, будет все больше и больше отставать от развитых стран.

С финансово-экономической точки зрения, страна живет за счет использования природных сырьевых и топливно-энергетических запасов и еще какое-то время может за их счет поддерживать достаточно приемлемый уровень жизни населения.

• Для того чтобы изменить ситуацию, нужен целый комплекс мер, поскольку необходимо решить следующие вопросы: для чего изменения, что делать в первую очередь, какую пользу получит от этого государство?

- Необходимо поднимать престиж образования. Престижность образования сегодня означает высокий уровень качества жизни выпускников ВУЗов. Остро стоят вопросы их трудоустройства, заработка, проживания, труда и социальных гарантий. Надо, чтобы образованный человек по закону мог стать честным миллионером, чтобы слово «бюджетник» не звучало как ругательство.

- Наука и ее разработки пронизывают все наше общество, хотим мы этого или нет. Охватить всю тематику исследований невозможно, поэтому возникает как международная кооперация базовых научных исследований, так и международное разделение направлений инновационной активности между разными странами. Возможно, именно здесь мы можем занять очень интересную нишу и найти то, что нам надо делать. Россия богата талантами. Придумать и создать один экземпляр чего угодно мы можем всегда. Запатентовать его - 
практически не получается: то денег нет, то времени, то терпения. Вот если бы государство здесь помогло и создало банк патентов, на условиях, взаимовыгодных и государству и изобретателю, то мы бы, наверное, превратились в самую мощную страну - патентодержателя. Это, прежде всего, относится к разработке, производству и внедрению новых современных технологий, т.е. осуществлению полного инновационного цикла. Вот где бы развернуться малому бизнесу! Но для этого надо готовить людей, решать вопросы выплат гонорара за изобретение, обеспечивать безопасность государства и передачи изобретений и технологий. В соответствии с действующим законом о патентовании, если подача заявки и ее регистрация осуществляется государственной организацией, то патентодержателем является организация, а не непосредственный исполнитель. Для примера в США, в этом случае, разработчику выплачивается 15\% гонорара, в странах ЕС $-8-10 \%$, в России - 0\%. Поэтому в США регистрируется столько заявок, сколько во всех других странах вместе взятых, а изобретателю выгодно только изобретать, а не внедрять свое творение.

- Конкурентоспособность наших товаров зависит от их себестоимости, качества и некоторых показателей. Если мы хотим, чтобы наши товары были конкурентоспособны на внешнем рынке, то они должны удовлетворять международным стандартам качества и иметь низкую себестоимость. А это означает, что нам нужны дешевое сырье и дешевая энергия внутри страны. Если естественные монополии не могут справиться с ростом цен, то функция государства решить эту проблему в стране.

Как видно из анализа, перед страной стоят не столько экономические, сколько социальные задачи, образующие базис общества, базис отношений между властью и обществом и внутри общества. Без этого базиса политика 
государства напоминает строительство современного корабля на старом, прогнившем остове. Ставя современное оборудование, мы одновременно ставим латки на корпус, чтобы не потонуть.

Многие из этих проблем были обозначены еще в майском послании 2006 года Федеральному собранию В.В. Путиным. Пришло время решать проблемы через новую идеологию - устойчивое развитие.

\section{Благодарности:}

1. Исследование выполнено при финансовой поддержке РГНФ в рамках проекта проведения научных исследований «Разработка подходов к созданию системы оценки состояния и определения перспективных направлений развития научной сферы», проект № 16-02-00407.

2. Исследование выполнено при финансовой поддержке РФФИ в рамках проекта проведения научных исследований «Возможности научно обоснованного выбора приоритетных направлений экологизации сельскохозяйственного производства и повышения его экономической эффективности», проект № 16-06-00029. 


\section{Литература:}

1. Горелов В.И. Управление развитием регионов. - М.: Экон-Информ, 2007, 163 стр.

2. Горелов В.И., Ледащева Т.Н., Карелова О.Л. Системное моделирование в социально-экономической сфере. - М.- Химки: РМАТ, 2012.-185c

3. Горелов В.И. Уроки Украины. Материалы конференции "Экономические проблемы устойчивого развития", г. Сумы, СНУ, Украина, 2014. http://fem.sumdu.edu.ua/ru/news/news/1957-materali-konferenc-qekonomchnproblemi-stalogo-rozvitkuq-2014-roku.html

4. С.Глазьев «Последняя геополитическая партия» М.: ж. Международная жизнь, август 2015 года, стр.2-25. 